Provided for non-commercial research and education use. Not for reproduction, distribution or commercial use.

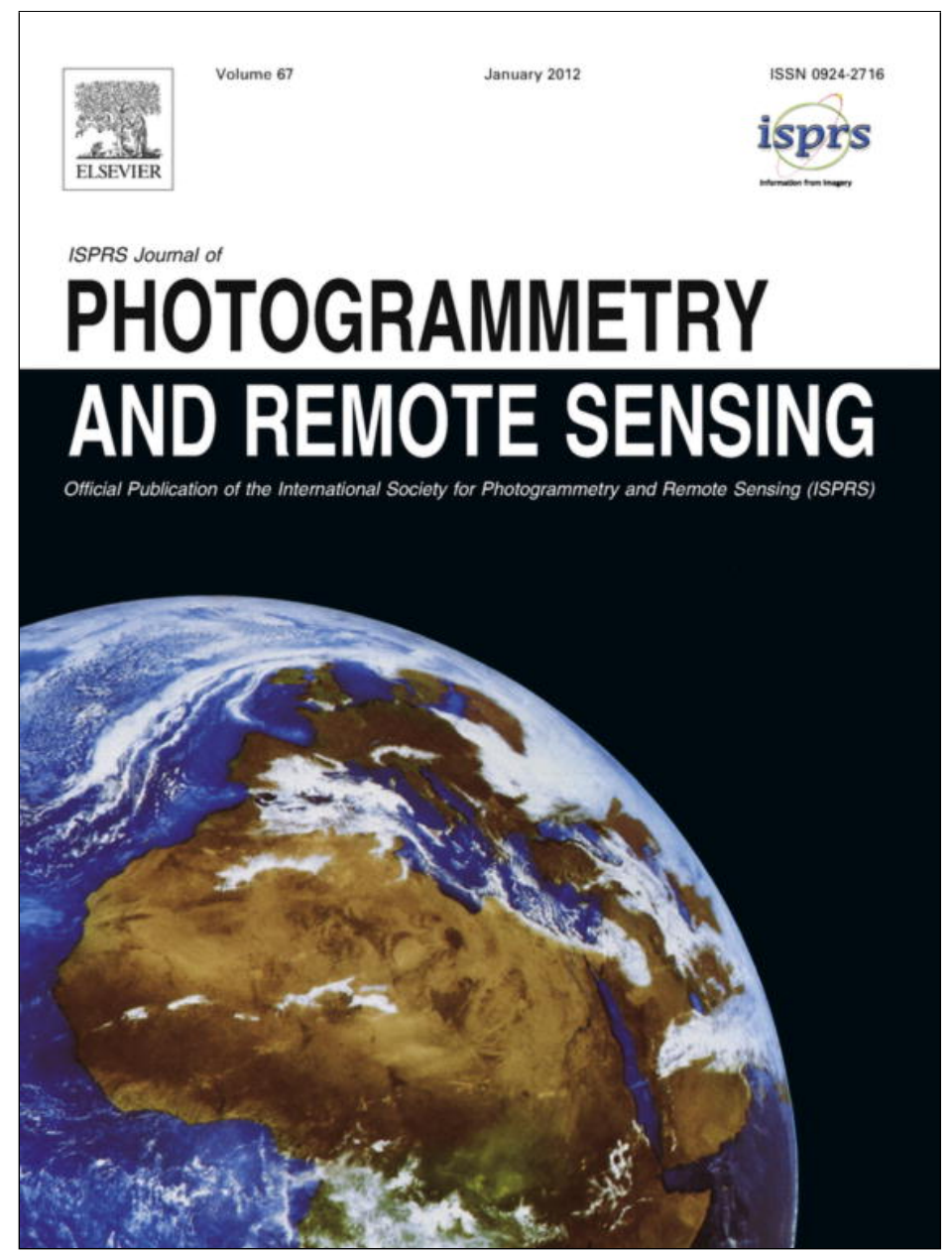

(This is a sample cover image for this issue. The actual cover is not yet available at this time.)

This article appeared in a journal published by Elsevier. The attached copy is furnished to the author for internal non-commercial research and education use, including for instruction at the authors institution and sharing with colleagues.

Other uses, including reproduction and distribution, or selling or licensing copies, or posting to personal, institutional or third party websites are prohibited.

In most cases authors are permitted to post their version of the article (e.g. in Word or Tex form) to their personal website or institutional repository. Authors requiring further information regarding Elsevier's archiving and manuscript policies are encouraged to visit:

http://www.elsevier.com/copyright 


\title{
A comparative analysis of ALOS PALSAR L-band and RADARSAT-2 C-band data for land-cover classification in a tropical moist region
}

\author{
Guiying Li ${ }^{\mathrm{a}, *}$, Dengsheng Lu ${ }^{\mathrm{a}}$, Emilio Moran ${ }^{\mathrm{a}}$, Luciano Dutra ${ }^{\mathrm{b}, 1}$, Mateus Batistella ${ }^{\mathrm{c}, 2}$ \\ ${ }^{a}$ Anthropological Center for Training and Research on Global Environmental Change (ACT), Indiana University, Student Building 331, 701 E. Kirkwood Ave., Bloomington, \\ IN 47405, USA \\ ${ }^{\mathrm{b}}$ National Institute for Space Research, Av. dos Astronautas, 1758, 12245-010 São Jose dos Campos, SP, Brazil \\ ${ }^{\mathrm{c}}$ Embrapa Satellite Monitoring, Av. Julio Soares de Arruda, 803, 13088-300 Campinas, SP, Brazil
}

\section{A R T I C L E I N F O}

\section{Article history:}

Received 11 March 2011

Received in revised form 2 February 2012

Accepted 29 March 2012

\section{Keywords:}

ALOS PALSAR

RADARSAT

Texture

Land-cover classification

Amazon

\begin{abstract}
A B S T R A C T
This paper explores the use of ALOS (Advanced Land Observing Satellite) PALSARL-band (Phased Array type L-band Synthetic Aperture Radar) and RADARSAT-2 C-band data for land-cover classification in a tropical moist region. Transformed divergence was used to identify potential textural images which were calculated with the gray-level co-occurrence matrix method. The standard deviation of selected textural images and correlation coefficients between them were then used to determine the best combination of texture images for land-cover classification. Classification results based on different scenarios with maximum likelihood classifier were compared. Based on the identified best scenarios, different classification algorithms - maximum likelihood classifier, classification tree analysis, Fuzzy ARTMAP (a neural-network method), k-nearest neighbor, object-based classification, and support vector machine were compared for examining which algorithm was suitable for land-cover classification in the tropical moist region. This research indicates that the combination of radiometric images and their textures provided considerably better classification accuracies than individual datasets. The L-band data provided much better landcover classification than C-band data but neither L-band nor C-band was suitable for fine land-cover classification system, no matter which classification algorithm was used. L-band data provided reasonably good classification accuracies for coarse land-cover classification system such as forest, succession, agropasture, water, wetland, and urban with an overall classification accuracy of $72.2 \%$, but C-band data provided only 54.7\%. Compared to the maximum likelihood classifier, both classification tree analysis and Fuzzy ARTMAP provided better performances, object-based classification and support vector machine had similar performances, and k-nearest neighbor performed poorly. More research should address the use of multitemporal radar data and the integration of radar and optical sensor data for improving land-cover classification.
\end{abstract}

(c) 2012 International Society for Photogrammetry and Remote Sensing, Inc. (ISPRS) Published by Elsevier B.V. All rights reserved.

\section{Introduction}

Land-cover classification based on remotely sensed data has attracted great attention since the launch of Landsat in the 1970s. Many classification methods, such as artificial neural networks, regression tree classifiers, support vector machines, object-based classifiers, and subpixel-based methods have been developed (Blaschke, 2010; Franklin and Wulder, 2002; Lu and Weng, 2007; Rogan et al., 2008; Tso and Mather, 2001). Although Landsat and

\footnotetext{
* Corresponding author. Tel.: +1 812856 5320; fax: +1 8128553000 .

E-mail addresses: ligu@indiana.edu (G. Li), dlu@indiana.edu (D. Lu), moran@ indiana.edu (E. Moran), dutra@dpi.inpe.br (L. Dutra), mb@cnpm.embrapa.br (M. Batistella).

1 Tel.: +55 123945 6475; fax: +55 1239456468 .

2 Tel.: +55 193256 6030; fax: +55 1932541100 .
}

other optical sensors have been successfully and heavily used for land-cover classification throughout the world's humid tropical biomes, cloud cover still presents a challenge to continuous observation that might be overcome or addressed using complementary techniques such as radar. As the electromagnetic waves in the microwave regions are almost not influenced by atmospheric interference, synthetic aperture radar (SAR) data can be acquired even in atmospheric conditions inappropriate for optical sensors (Kasischke et al., 1997). Therefore, radar data have become an important source for land-cover classification in the past decade (Baghdadi et al., 2009; Dutra and Huber, 1999; Martinez and Le Toan, 2007; Park, 2010; Park and Chi, 2008; Rajesh et al., 2001; Saatchi et al., 2000). The launches of satellite radar sensors such as RADARSAT (http://www.radarsat2.info/, accessed 29 March, 2012) and Advanced Land Observing Satellite (ALOS) Phased Array 
type L-band Synthetic Aperture Radar (PALSAR) (Rosenqvist et al., 2007) provide an alternative source for land-cover classification in the tropical moist regions (Evans et al., 2010; Rakwatin et al., 2010), because they can provide all-weather land observation, which is especially valuable when optical sensor data are not available due to cloud cover.

Radar data are often acquired at one wavelength with different polarization options. How to effectively use the spatial information inherent to the radar data to generate new images becomes an important research topic. Texture is often referred to as the pattern of intensity variations in an image, and has become valuable in improving land-cover classification accuracy (Augusteijn et al., 1995; Chen et al., 2004; Franklin et al., 2000; Lu et al., 2007; Marceau et al., 1990; ndi Nyoungui et al., 2002; Podest and Saatchi, 2002; Saatchi et al., 2000; Sawaya et al., 2010). Although many texture measures have been developed (Haralick et al., 1973; Kashyap et al., 1982; Milne and Dong, 2002; Rajesh et al., 2001), it is unclear which textures are useful in improving the separability of vegetation types (e.g., different primary forest types and successional stages) (Sawaya et al., 2010), especially in tropical moist regions due to the complex forest stand structure and species composition. The difficulty in identifying suitable textural images for a specific study is due to textures that vary with the characteristics of the landscape under investigation, the texture measure selected, the size of the moving window, and the image itself (Chen et al., 2004; Franklin et al., 1996). It is also poorly understood which polarization option corresponding to which wavelength allows better vegetation classification in the tropical moist region (Evans et al., 2010). Therefore, this study aims to explore the use of ALOS PALSAR L-band (hereafter L-band) and RADARSAT-2 C-band (hereafter C-band) data in land-cover classification in tropical moist region. Specifically, this study is designed to (1) identify which polarization options corresponding to L-band and C-band and which texture measures are most suitable for vegetation separation, (2) determine how detailed a vegetation classification system can be while maintaining high accuracy, and (3) explore the incorporation of textural images and radiometric data for improving land-cover, especially vegetation, classification.

In land-cover classification, selection of a suitable classification algorithm is another important research topic (Lu and Weng, 2007). Although a large number of algorithms, from traditional maximum likelihood classifier to advanced algorithms such as neural network, decision tree, support vector machines, objectbased algorithms, subpixel-based algorithms, and contextual algorithms (Blaschke, 2010; Franklin and Wulder, 2002; Frery et al., 2007; Lu and Weng, 2007; Rogan et al., 2008; Tso and Mather, 2001) are available, it is not clear which classification algorithm is suitable for radar data for vegetation classification in the tropical moist region. Therefore, another objective of this study is to compare different classification algorithms-maximum likelihood classifier, classification tree analysis, Fuzzy ARTMAP (a neural-network method), k-nearest neighbor, object-based classification, and support vector machine-based on the identified best scenarios for identifying a suitable algorithm for land-cover classification.

\section{Study area}

Altamira is located along the Transamazon Highway (BR-230) in the northern Brazilian state of Pará (Fig. 1). The study area covers approximately $3116 \mathrm{~km}^{2}$. The dominant native vegetation types are mature moist forest and liana forest. Major deforestation began in the early 1970s, coincident with the construction of the Transamazon Highway (Moran, 1981). Extensive deforestation has occurred since the 1980 s, which has led to a complex landscape consisting of different succession stages, pasture, and agricultural lands (Moran and Brondízio, 1998; Moran et al., 1994a,b). Various stages of successional vegetation are distributed along the Transamazon Highway and feeder roads. Annual rainfall in Altamira is approximately $2000 \mathrm{~mm}$ and is concentrated from late October through early June; the dry period occurs between June and September. Average temperature is about $26^{\circ} \mathrm{C}$.

\section{Methods}

\subsection{Field data collection and determination of land-cover classification systems}

Sample plots for different land cover types, especially for different stages of secondary succession and pasture were collected in the Altamira study area during July-August 2009. In this study area, primary forest is distributed away from the roads, and different succession stages, pastures, and agricultural lands are distributed along the main and secondary roads, forming the familiar "fishbone" pattern of deforestation. Because of the difficulty in accessing forested sites in tropical moist regions like this study area, random allocation of sample plots for field survey is not feasible. Therefore, candidate sample locations of complex vegetation areas were first selected in the laboratory. The majority of sample plots relevant to non-forest vegetation and pastures were allocated along the road sides. In each sample area, the locations of different vegetation types and detailed descriptions of vegetation stand structures (e.g., height, canopy cover, composition of dominant tree species) were recorded during the field survey. Meantime, photos were taken for each vegetation type. The sample plots were used to create representative Region of Interest (ROI) polygons. A total of 432 sample plots were collected, including 220 ROIs for use as training sample plots during image classification and the rest 212 ROIs for use as test sample plots for accuracy assessment. According to the research objectives, compatibility with previous work (Mausel et al., 1993; Moran and Brondízio, 1998; Moran et al., 1994a,b) and field surveys, three forest classes (upland, flooding, and liana forest), three succession stages (initial [SS1], intermediate [SS2], and advanced [SS3]), agropasture, and three non-vegetated classes (water, wetland, and urban) were designed for the land-cover classification system. Meanwhile, a second classification system consisting of forest (by merging upland, flooding and liana forest as one class), succession (by merging SS1, SS2 and SS3 as one class), agropasture, water, wetland, and urban was also examined.

\subsection{Radar data collection and preprocessing}

In this study, we used the ALOS PALSARFBD (Fine Beam Double Polarization) Level 1.5 products with $\mathrm{HH}$ and HV polarization options (ground range, unsigned 16-bit integer number, $12.5-\mathrm{m}$ pixel spacing) (http://www.eorc.jaxa.jp/ALOS/en/about/palsar.htm), and RADARSAT-2 standard beam mode SGX (SAR Georeferenced Extra) product with $\mathrm{HH}$ and $\mathrm{HV}$ polarization options (ground range, unsigned 16-bit integer number, 8-m pixel spacing) (http:// www.radarsat2.info/). The ALOS PALSAR L-band images were acquired on 2 July 2009 and RADARSAT-2 C-band images were acquired on 30 August 2009. The radar image quality was carefully examined. Some null pixels in the urban area were found in the L-band data due to the impacts of tall objects. The null pixels were first detected, and then replaced with a median value from the pixels within a $5 \times 5$ window based on the null pixel as a center point. Both L-band and C-band images were registered to a georectified Landsat 5 Thematic Mapper (TM) image (UTM coordinate system, zone 22, south). For L-band images, the root mean square error (RMSE) was 1.020 pixels ( $x$ error: $0.914, y$ error: 0.452 ) based on 


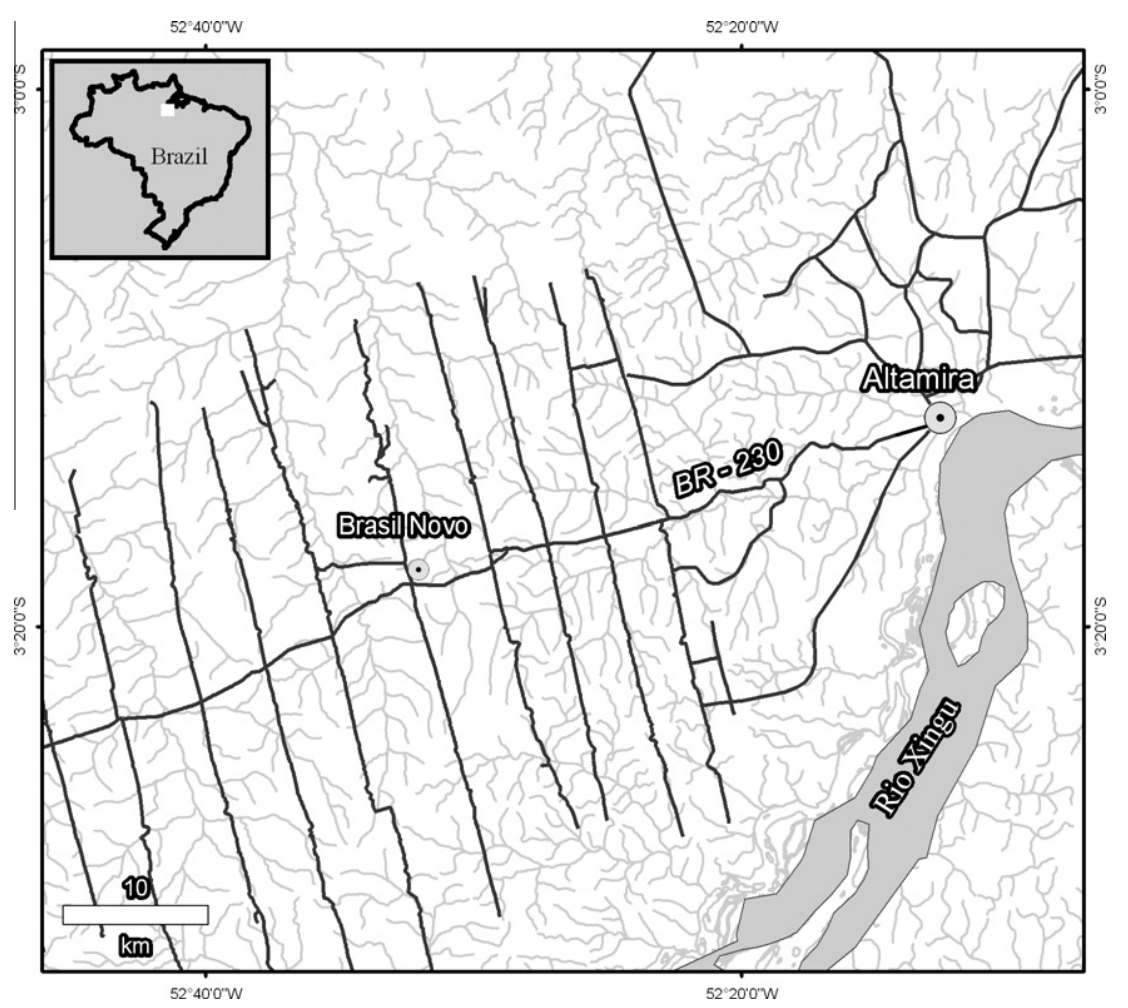

Fig. 1. Study area - Altamira, Pará State, Brazil.

28 control points. For C-band, the RMSE was 1.395 pixels ( $x$ error: 1.067, $y$ error: 0.899) based on 15 control points. Both radar images were resampled to a pixel size of $10 \mathrm{~m}$ by $10 \mathrm{~m}$ with the nearestneighbor technique during the image-to-image registration. In order to make full use of both $\mathrm{HH}$ and $\mathrm{HV}$ data features, a new image was calculated by $\mathrm{NL}=(\mathrm{HH} * \mathrm{HV}) /(\mathrm{HH}+\mathrm{HV})$. Both L-band and Cband data were saved in digital number (amplitude) with unsigned 16-bit integer data range.

The speckle in a radar image is often a problem and should be reduced before the radar image is used for further quantitative analysis. Different speckle reduction methods such as median, Lee-Sigma, Gamma-Map, local-region, and Frost (Lee et al., 1994) have been developed. One important decision is to select a suitable window size for use in the filtering method. In general, the following criteria are used to identify the best filtering method: (1) speckle reduction, (2) edge sharpness preservation, (3) line and point target contrast preservation, (4) retention of texture information, and (5) computational efficiency (Lee et al., 1994; ndi Nyoungui et al., 2002). In this study, median, Lee-Sigma, Gamma-Map, local-region, and Frost with window sizes of $3 \times 3,5 \times 5,7 \times 7$, and $9 \times 9$, respectively, were examined. A comparative analysis by visual interpretation of the filtered images and the time required for image processing indicated that Lee-Sigma and Frost methods were similar, but the Frost method required much longer time for image processing than the Lee-Sigma method. Finally, the Lee-Sigma with a window size of $5 \times 5$ pixels was selected for this study. The speckle-reduced radar images were directly used for land-cover classification. Meanwhile, textural images were developed from the raw radar images by using different texture measures and various window sizes.

\subsection{Selection of suitable textural images}

Of the many texture measures, the gray-level co-occurrence matrix (GLCM) may be the most common method used for improving land-cover classification (Franklin et al., 2000; Li et al., 2011; Lu et al., 2007; Marceau et al., 1990; ndi Nyoungui et al., 2002). In this study, six GLCM-based texture measures (variance, homogeneity, contrast, dissimilarity, entropy, and second moment; see Table 1 for the formulas) with six window sizes $(5 \times 5,9 \times 9,15 \times 15$, $19 \times 19,25 \times 25$, and $31 \times 31$ ) were applied to the $\mathrm{HH}, \mathrm{HV}$ and $\mathrm{NL}$ images from both L-band and C-band data for identifying the best texture measure and associated best window size for producing the textural images. Separability analysis was conducted based on different scenarios, that is, individual images and combinations of two or more textural images, in order to identify the best single textural images and the best combination of textural images for vegetation classification.

Different separability analysis methods, such as Euclidean distances, divergence, transformed divergence, and Jeffries-Matusita distance can be used (Landgrebe, 2003; Mausel et al., 1993; Sheoran, 2009). In particular, the transformed divergence algorithm is often used in practice and thus used in this study. The transformed divergence values range from 0 to 2000. Usually, a value of greater than 1900 implies a good separability between two land cover types, while a value of less than 1700 is regarded as poor

Table 1

Texture measures used in research.

\begin{tabular}{lll}
\hline No. & Texture measures & Formula \\
\hline 1 & Variance (VAR) & VAR $=\sum_{i, j=0}^{N-1} P_{i, j}(i-\mathrm{ME})^{2}$ \\
2 & Homogeneity (HOM) & $\mathrm{HOM}=\sum_{i, j=0}^{N-1} \frac{P_{i, j}}{1+(i-j)^{2}}$ \\
3 & Contrast (CON) & $\mathrm{CON}=\sum_{i, j=0}^{N-1} P_{i, j}(i-j)^{2}$ \\
4 & Dissimilarity (DIS) & $\mathrm{DIS}=\sum_{i, j=0}^{N-1} P_{i, j}|i-j|$ \\
5 & Entropy (ENT) & $\mathrm{ENT}=\sum_{i, j=0}^{N-1} P_{i, j}\left(-\ln P_{i, j}\right)$ \\
6 & Second Moment (SM) & $\mathrm{SM}=\sum_{i, j=0}^{N-1} P_{i, j}^{2}$ \\
\hline
\end{tabular}

Notes: $P_{i, j}=V_{i, j} / \sum_{i, j=0}^{N-1} V_{i, j}, M E=\sum_{i, j=0}^{N-1} i\left(P_{i, j}\right)$, where $V_{i, j}$ is the value in the cell $i, j$ (row $i$ and column $j$ ) of the moving window and $N$ is the number of rows or columns. 
separation between two classes. When two or more textural images are used, the separability analysis may provide many potential pairs with the same or similar transformed divergence values. Lu et al. (2008) proposed to identify the best combination based on transformed divergence values and correlation coefficients. However, due to the similar transformed divergence values, this method cannot determine the best combination for vegetation classification. Because not all textural images are useful in improving vegetation classification, or many textures have similar information, it is necessary to identify the best textural images for maximizing the separation of land-cover classes of interest. In general, a higher standard deviation value of an image indicates a higher information load, implying better performance for landcover classification. Therefore, this study modified the previously used method by replacing transformed divergence with standard deviation. When the potential combinations of textural images are selected on the basis of transformed divergence analysis, the best combination is determined from the analysis of standard deviation and correlation coefficients according to Eq. (1):

Best combination $=\left(\sum_{i=1}^{n} S T D_{i}\right) /\left(\sum_{j}^{n}\left|R_{i j}\right|\right)$,

where $S T D_{i}$ is the standard deviation of the textural image $i, R_{i j}$ is the correlation coefficient between textural images $i$ and $j$, and $n$ is the number of textural images. A higher best combination value indicates a better combination of textural images for vegetation classification.

\subsection{Land-cover classification with maximum likelihood classifier based on different scenarios}

In order to identify which polarization option and which texture measure provide the best classification, and to explore the roles of textural images in improving land-cover classification, especially for vegetation, in the tropical moist region, different scenarios were designed and summarized in Table 2. Maximum likelihood classifier was used to conduct land-cover classification for each scenario. Based on the field survey and a 2008 QuickBird image, a total of 220 sample plots (over 3500 pixels) covering the 10 land cover types, each consisting of 15-30 plots, were used for image classification. The classification results were evaluated with the error matrix method, as discussed in Section 3.6. The best scenario was further analyzed with different classification algorithms.

\subsection{Comparison of land-cover classification results from different classification algorithms}

Six classification algorithms - maximum likelihood classifier, knearest neighbor, Fuzzy ARTMAP (a neural network classification method that synthesizes fuzzy logic and Adaptive Resonance
Theory models), classification tree analysis, object-based classification, and support vector machine - were selected to examine which classification algorithm provided the best classification. Maximum likelihood classifier is the most common parametric classifier that assumes normal or near normal distribution for each feature of interest and an equal prior probability among the classes. This classifier is based on the probability that a pixel belongs to a particular class. It takes the variability of classes into account by using the covariance matrix (Jensen, 2005). Because maximum likelihood classifier is often criticized for its requirement of normal distribution, other nonparametric algorithms are regarded as having more advantages than traditional parametric classification algorithms (Lu et al., 2004; Pal and Mather, 2003), thus they are examined in this study. Much previous literature has detailed these methods, such as classification tree analysis (Elnaggar and Noller, 2010; Friedl and Brodley, 1997), Fuzzy ARTMAP (Carpenter et al., 1991; Gamba and Dell'Aqua, 2003; Li, 2008), k-nearest neighbor (Maselli et al., 2005; McRoberts and Tomppo, 2007), object-based classification (Blaschke, 2010; Yu et al., 2006), and support vector machine (Camps-Valls and Bruzzone, 2009; Mountrakis et al., 2011; Perumal and Bhaskaran, 2009). Therefore, this paper did not provide a detailed description of these classification algorithms. The same training samples were used for each classification method.

\subsection{Evaluation of classification results}

The error matrix method is often used for evaluation of landcover classification results. This method provides a detailed assessment of the agreement between the classified result and reference data, and provides information on how the misclassification happened (Congalton and Green, 2008). Other accuracy assessment parameters, such as overall classification accuracy, producer's accuracy, user's accuracy, and kappa coefficient are calculated from the error matrix, as much previous literature has described (e.g., Congalton, 1991; Congalton and Green, 2008; Foody, 2002, 2009; Smits et al., 1999; Wulder et al., 2006). Both overall accuracy and kappa coefficient reflect the overall classification performance but cannot provide a measure of reliability of each land-cover class; thus, producer's accuracy and user's accuracy for each class are often used to provide the complementary analysis of the accuracy assessment. In this study, a total of 212 test sample plots from the field survey and a 2008 QuickBird image were used for accuracy assessment, with 12-33 plots for each land cover. An error matrix was developed for each classified image, producer's accuracy and user's accuracy for each class and overall accuracy and kappa coefficient for each classified image were calculated from the relevant error matrix. Although randomly sampling method for collecting test samples was not used in this study because of the difficulty in accessing field sites, use of the same test samples from field survey and a QuickBird image for each scenario and

Table 2

Design of different scenarios based on ALOS PALSAR L-band and RADARSAT-2 C-band data for land-cover classification.

\begin{tabular}{|c|c|c|}
\hline No. & Scenarios & Examples of labels \\
\hline 1 & Single polarization image: $\mathrm{HH}, \mathrm{HV}$, and NL (3 scenarios) & $\mathrm{HH}$ \\
\hline 2 & Textural images: selected textural images corresponding to single-polarization option ( 3 scenarios) & HH-text \\
\hline 3 & Combination of single-polarization image and relevant textural images ( 3 scenarios) & HH\&text \\
\hline 4 & Combination of single-polarization options ( 2 scenarios) & HH\&HV \\
\hline 5 & Combination of textural images from different, individual polarization options ( 2 scenarios) & HH-\&HV-text \\
\hline 6 & Combination of single-polarization options and their relevant textural images ( 2 scenarios) & HH\&HV\&text \\
\hline 7 & Combination of $\mathrm{HH}$ and HV from both L-band and C-band data & L\&CHH\&HV \\
\hline 8 & Combination of textural images from $\mathrm{HH}$ and $\mathrm{HV}$ of both L-band and C-band data & L \& C HH-\&HV-text \\
\hline 9 & Combination of single-polarization options and their relevant textural images from both L-band and C-band data & L \& C HH\&HV\&text \\
\hline
\end{tabular}

Notes: Scenarios 1-6 are for ALOS PALSAR L-band and for RADARSAT-2 C-band data; scenarios 7-9 are for the combination of both radar datasets. The “-” and "\&"in this table indicate "derived" and "combination," for example, HH-text indicates textural images derived from HH image, HH\&HV represents the combination of HH and HV images. 
for each classification algorithm can make sure that the comparison of these classification results is reliable.

\section{Results and discussion}

\subsection{Identification of best polarization option and textural images}

The separability analysis based on training samples implies that a single $\mathrm{HV}, \mathrm{HH}$, or NL image cannot effectively separate the vegetation types. For example, the average transformed divergence values based on the training sample plots of vegetation types for the L-band $\mathrm{HH}$ and $\mathrm{HV}$ images were only 1739 and 1756, respectively. A combination of L-band $\mathrm{HH}$ and HV images improved the separability, and the average value became 1908 . This study indicates that the radiometric data, either L-band or C-band, are not sufficient to separate vegetation types. New images need to be developed from the radiometric data. Texture measures can produce new images by making use of spatial information inherent in the image.

For each polarization image, such as $\mathrm{HH}$, there are 36 textural images based on six texture measures and six window sizes. The transformed divergence analysis indicates that the majority of single textural images have relatively poor capability of vegetation separation. Table 3 provided the textural images when average transformed divergence values were over 1950. A window size of $25 \times 25$ for $\mathrm{HH}$ and $\mathrm{HV}$ images from both L-band and C-band data was best, but a $31 \times 31$ window size for the NL image was best. The best texture measure varied, depending on different polarization images. Overall, the transformed divergence analysis indicates that a single textural image cannot effectively separate vegetation types, especially between succession stages.

For a combination of two textural images on a single polarization image, there are 630 potential combinations. According to transformed divergence analysis based on two textural images, the results show that a combination of two textural images can improve vegetation separability. When both minimum and average transformed divergence values for vegetation types based on training samples were more than 1950, the potential textural images with the highest transformed divergence values (some combinations have the same values of 2000) are summarized in Table 3 too. Analysis of the best combination values indicates that the best combinations of two textural images vary, depending on different polarization options. For L-band HH or HV image, both second moment and contrast with window sizes of $19 \times 19,25 \times 25$, and $31 \times 31$ provided the best results. For C-band $\mathrm{HH}$ or HV image, textural images based on homogeneity with a $31 \times 31$ window and with dissimilarity or contrast associated with a $25 \times 25$ window size provided the best results. Fig. 2 provides a comparison of $\mathrm{HH}, \mathrm{HV}$, and NL from L-band and C-band data and two selected textural images corresponding to each polarization option, indicating the different features between them. For example, the selected textural images in Fig. 2b and c have significantly different appearances with respect to land features, such as water (river here) and urban. Therefore, the combination of both texture images that have complementary information provides the potential to improve land-cover classification.

\subsection{Comparison of classification results among scenarios on a fine- classification system}

A comparison of classification results among single polarization options, textural images corresponding to the polarization image, and combinations of single polarization images and related textural images are summarized in Table 4 . Table 4 shows that L-band $\mathrm{HH}$ and NL images perform similarly in land-cover classification and both are better than the HV image. The NL-derived textural images are better than HH- or HV-derived textural images. A combination of individual polarization images and corresponding textural images improved classification accuracy by $5.7-9.9 \%$ compared to a single polarization image, and such a combination is especially valuable for improving vegetation classification. For C-band data, pure radiometric or textural images cannot classify some land-cover types such as liana forest, SS2, and SS3. The classification results based on C-band $\mathrm{HH}, \mathrm{HV}$, and $\mathrm{NL}$ images, their textures, and their combinations have much lower classification accuracy than corresponding L-band data, implying that longwavelength data (i.e., L-band) perform better in classification, especially for vegetation, than short-wavelength data (i.e., C-band). Table 4 also indicates that NL image did not provide better classification than $\mathrm{HH}$ for L-band, but the textures from NL image improved classification than the textures from $\mathrm{HH}$ or HV images. In addition to the similar results for textures from C-band $\mathrm{NL}$ image, incorporation of textures into NL image improved land-cover classification than the combination of $\mathrm{HH}$ or $\mathrm{HV}$ and corresponding textures.

A comparison of classification results based on the combination of different polarization options, textural images, and their combinations are summarized in Table 5 . Compared to Table 4, for Lband data, the combination of $\mathrm{HH}$ and $\mathrm{HV}$, the combination of their textural images, or the combination of both polarization options and textural images improved land-cover classification compared to individual polarization options or related textures. However,

Table 3

Identification of textural images for land-cover classification.

\begin{tabular}{|c|c|c|c|}
\hline \multirow[t]{2}{*}{ Data } & \multicolumn{2}{|l|}{ Potential textures } & \multirow[t]{2}{*}{ Selected textures } \\
\hline & Single textures & Combinations & \\
\hline $\begin{array}{r}\text { ALOS PALSAR } \\
\text { L-band HH }\end{array}$ & SM25, ENT25, SM31 & VAR31-DIS31, ENT25-SM31, DIS31-ENT31, SM25-CON31, ENT19-SM25, VAR31-CON31 & SM25-CON31 \\
\hline $\begin{array}{l}\text { ALOS PALSAR } \\
\text { L-band HV }\end{array}$ & $\begin{array}{l}\text { CON25, CON31, CON19, } \\
\text { and DIS25 }\end{array}$ & $\begin{array}{l}\text { CON25 with all selected texture with window sizes greater than } 15 \times 15 \text {; DIS25-CON31, } \\
\text { VAR25-CON31, CON19-DIS25 }\end{array}$ & CON25-SM19 \\
\hline $\begin{array}{l}\text { ALOS PALSAR } \\
\text { L-band NL }\end{array}$ & ENT31, DIS25, and ENT25 & $\begin{array}{l}\text { DIS25-CON31, CON25-DIS31, DIS19-DIS31, DIS25-ENT31, DIS15-DIS25, SM25-VAR31, } \\
\text { VAR25-DIS25, SM25-DIS31 }\end{array}$ & SM25-VAR31 \\
\hline $\begin{array}{l}\text { RADARSAT-2 } \\
\text { C-band HH }\end{array}$ & DIS25, HOM25, DIS15 & DIS15-CON31, DIS25-HOM31, DIS19-CON31, CON15-DIS25 & DIS25-HOM31 \\
\hline $\begin{array}{l}\text { RADARSAT-2 } \\
\text { C-band HV }\end{array}$ & CON25, DIS25, HOM25, CON31 & DIS25 (or CON25) with most textures; HOM31-DIS31, CON19-HOM31 (or ENT31) & CON25-HOM31 \\
\hline $\begin{array}{l}\text { RADARSAT-2 } \\
\text { C-band NL }\end{array}$ & SM31, ENT19 & ENT19-ENT31, SM19-ENT31 & SM19-ENT31 \\
\hline
\end{tabular}

Notes: CON (contrast), DIS (dissimilarity), ENT (entropy), HOM (homogeneity), SM (second moment), and VAR (variance) represent the texture measures summarized in Table 1 . The number with each texture measure represents window size; for example, SM25 represents the second moment with a window size of $25 \times 25$ pixels. 

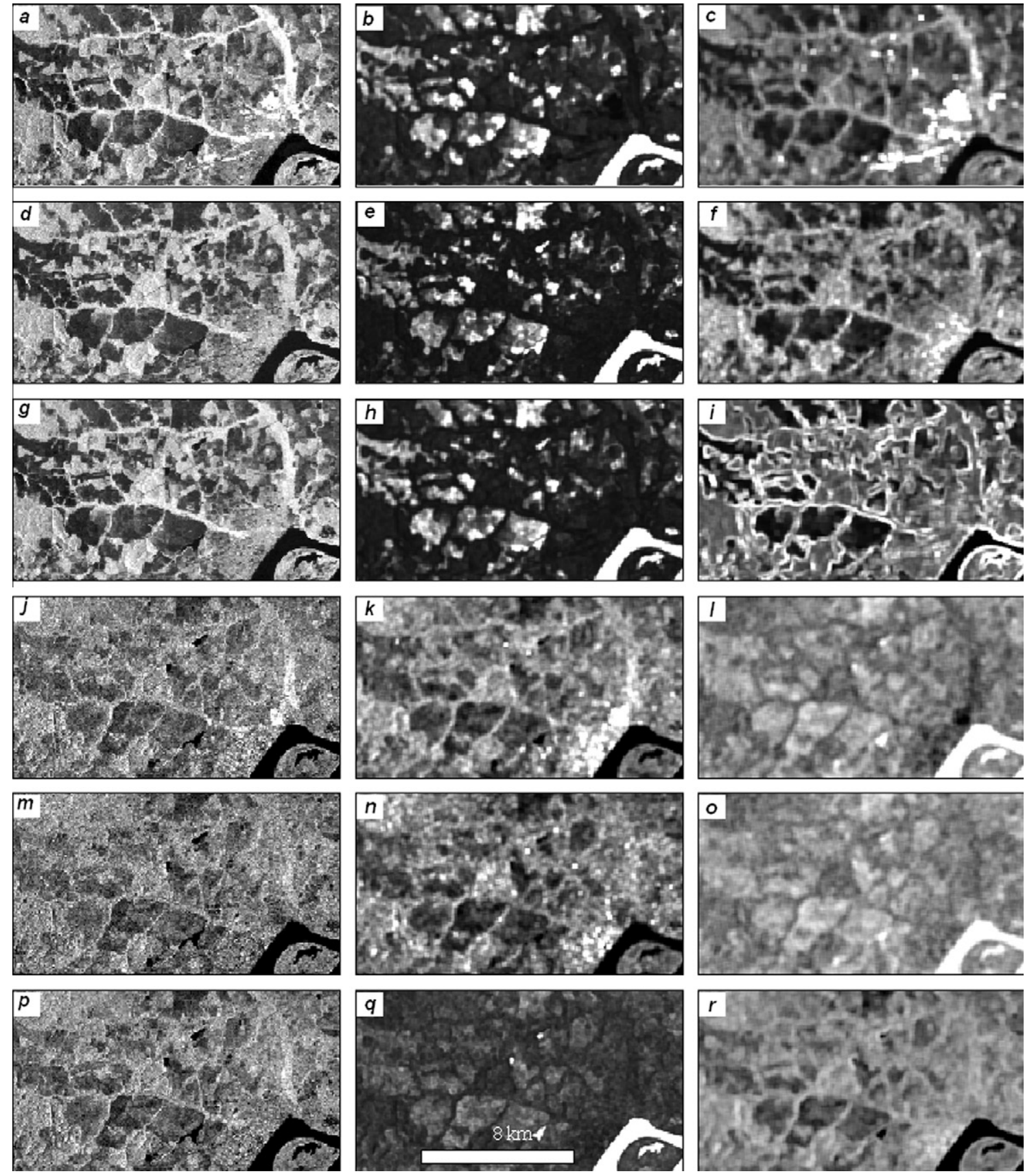

Fig. 2. A comparison of HH, HV, and NL from ALOS PALSAR L-band and RADARSAT-2 C-band and their corresponding textural images (see Table 3 for the selected textures), which were identified as the best combinations of textural images based on the best combination method. a, b, and c are ALOS PALSAR L-band HH image and HH-derived SM25 and CON31 textural images; d, e, and f are ALOS PALSAR L-band HV image and HV-derived CON25 and SM19 textural images; g, h, and i are ALOS PALSAR L-band NL image and NL-derived SM25 and VAR31 textural images; $\mathrm{j}, \mathrm{k}$, and $\mathrm{l}$ are RADARSAT-2 C-band HH image and HH-derived DIS25 and HOM31 textural images; $\mathrm{m}, \mathrm{n}$, and $\mathrm{o}$ are RADARSAT-2 C -band HV image and HV-derived CON25 and HOM31 textural images; p, q, and r are RADARSAT-2 C-band NL image and NL-derived SM19 and ENT31 textural images; CON, DIS, ENT, HOM, SM, and VAR represent contrast, dissimilarity, entropy, homogeneity, second moment, and variance as summarized in Table 1; the number with each texture measure represents window size, for example, SM25 represents the second moment with a window size of $25 \times 25$ pixels.

the addition of the NL image into the $\mathrm{HH}$ and $\mathrm{HV}$ combination slightly reduced the classification accuracy, possibly due to the high correlation coefficients of the NL image with the $\mathrm{HH}$ and $\mathrm{HV}$ images. For example, the correlation coefficients for L-band were 0.63 between $\mathrm{HH}$ and $\mathrm{HV}, 0.83$ between $\mathrm{HH}$ and NL, and 0.96 between HV and NL. For C-band data, a simple combination of C-band $\mathrm{HH}$ and $\mathrm{HV}$ or the combination of $\mathrm{HH}, \mathrm{HV}$, and NL did not significantly improve classification, possibly due to the poor performance of each polarization in land-cover, especially vegetation classification, as shown in Table 4. However, incorporation of NL-derived textural images either from L-band or C-band is valuable. Table 5 also shows that the L-band images provided much higher accuracies than the $\mathrm{C}$-band images.

A comparison of classifications among different scenarios is better illustrated in Fig. 3 based on the kappa coefficient. For L-band data, the combination of $\mathrm{HH}, \mathrm{HV}$, and their related textural images or the combination of $\mathrm{HH}, \mathrm{HV}, \mathrm{NL}$, and their related textural images provided the best classifications with kappa coefficients of over 0.5. For C-band, the best results were from the same combination as Lband data, but also included the scenario based on all textural 
Table 4

Comparison of land-cover classification results among the individual band, textural images, and the combination of individual band and related textural images from ALOS PALSAR L-band and RADARSAT-2 C-band data.

\begin{tabular}{|c|c|c|c|c|c|c|c|c|c|c|c|c|}
\hline \multirow[t]{3}{*}{ Land-cover type } & \multicolumn{6}{|c|}{ ALOS PALSAR L-band } & \multicolumn{6}{|c|}{ RADARSAT-2 C-band } \\
\hline & \multicolumn{2}{|l|}{$\mathrm{HH}$} & \multicolumn{2}{|c|}{ HH-text } & \multicolumn{2}{|c|}{ HH\&text } & \multicolumn{2}{|l|}{$\mathrm{HH}$} & \multicolumn{2}{|c|}{ HH-text } & \multicolumn{2}{|c|}{ HH\&text } \\
\hline & PA & UA & PA & UA & PA & UA & PA & UA & PA & UA & PA & UA \\
\hline UPF & 18.2 & 40.0 & 6.1 & 66.7 & 42.4 & 58.3 & - & - & 21.2 & 30.4 & 9.1 & 11.5 \\
\hline FLF & 66.7 & 43.5 & 26.7 & 25.0 & 80.0 & 60.0 & 66.7 & 13.3 & 6.7 & 10.0 & - & - \\
\hline LIF & - & - & 8.3 & 16.7 & 33.3 & 14.3 & - & - & - & - & 33.3 & 11.8 \\
\hline SS1 & 42.1 & 25.0 & 21.1 & 30.8 & 36.8 & 28.0 & - & - & 10.5 & 40.0 & 15.8 & 11.1 \\
\hline SS2 & 37.5 & 19.6 & 37.5 & 56.3 & 62.5 & 51.7 & - & - & - & - & 12.5 & 12.5 \\
\hline SS3 & 33.3 & 25.9 & 4.8 & 10.0 & 23.8 & 41.7 & - & - & - & - & 23.8 & 27.8 \\
\hline AGP & 76.9 & 54.1 & 69.2 & 62.1 & 69.2 & 60.0 & 76.9 & 20.6 & 50.0 & 59.1 & 73.1 & 57.6 \\
\hline WAT & 95.8 & 92.0 & 83.3 & 90.9 & 87.5 & 91.3 & 95.8 & 100.0 & 91.7 & 100.0 & 91.7 & 100.0 \\
\hline WET & - & - & 20.0 & 4.6 & 13.3 & 28.6 & - & - & 26.7 & 12.5 & 13.3 & 40.0 \\
\hline URB & 26.1 & 85.7 & 73.9 & 53.1 & 52.2 & 85.7 & 21.7 & 33.3 & 56.5 & 21.0 & 39.1 & 56.3 \\
\hline OCA & \multicolumn{2}{|c|}{41.98} & \multicolumn{2}{|c|}{32.75} & \multicolumn{2}{|c|}{51.89} & \multicolumn{2}{|c|}{27.36} & \multicolumn{2}{|c|}{29.25} & \multicolumn{2}{|c|}{33.02} \\
\hline \multirow[t]{2}{*}{ OKC } & \multicolumn{2}{|c|}{0.350} & \multicolumn{2}{|c|}{0.307} & \multicolumn{2}{|c|}{0.464} & \multicolumn{2}{|c|}{0.191} & \multicolumn{2}{|c|}{0.211} & \multicolumn{2}{|c|}{0.253} \\
\hline & HV & & HV-te & & HV\&t & & HV & & HV-te & & HV\&t & \\
\hline UPF & - & - & 21.2 & 31.8 & 30.3 & 31.3 & - & - & 18.2 & 40.0 & 18.2 & 40.0 \\
\hline FLF & 60.0 & 25.7 & 6.7 & 20.0 & 53.3 & 34.8 & - & - & - & - & 13.3 & 11.1 \\
\hline LIF & 33.3 & 12.1 & 25.0 & 25.0 & 41.7 & 20.0 & - & - & 25.0 & 8.6 & 33.3 & 16.0 \\
\hline SS1 & 31.6 & 25.0 & - & - & 42.1 & 34.8 & 36.8 & 8.4 & - & - & 31.6 & 15.0 \\
\hline SS2 & 50.0 & 25.0 & 33.3 & 61.5 & 50.0 & 52.2 & 45.8 & 20.8 & 12.5 & 10.3 & 12.5 & 37.5 \\
\hline SS3 & - & - & 14.3 & 37.5 & 14.3 & 15.0 & - & - & - & - & 23.8 & 22.7 \\
\hline AGP & 88.5 & 48.9 & 61.5 & 76.2 & 88.5 & 65.7 & - & - & 38.5 & 41.7 & 65.4 & 40.5 \\
\hline WAT & 95.8 & 100.0 & 91.7 & 91.7 & 91.7 & 100.0 & 100.0 & 100.0 & 91.7 & 100.0 & 91.7 & 100.0 \\
\hline WET & - & - & 53.3 & 23.5 & 13.3 & 50.0 & - & - & 6.7 & 10.0 & 13.3 & 28.6 \\
\hline URB & - & - & 52.2 & 16.7 & 4.4 & 20.0 & 52.2 & 24.0 & 60.9 & 24.6 & 39.1 & 69.2 \\
\hline OCA & & & & & & & & & & & & \\
\hline OKC & & & & & & & & & & & & \\
\hline & $\mathrm{NL}$ & & NL-te & & NL\&t & & $\mathrm{NL}$ & & NL-tes & & NL\&te & \\
\hline UPF & 6.1 & 20.0 & 18.2 & 60.0 & 42.4 & 53.9 & - & - & 27.3 & 28.1 & 30.3 & 28.6 \\
\hline FLF & 80.0 & 38.7 & 6.7 & 14.3 & 53.3 & 61.5 & - & - & 13.3 & 20.0 & 26.7 & 26.7 \\
\hline LIF & 50.0 & 18.8 & 25.0 & 15.8 & 41.7 & 13.2 & - & - & - & - & - & - \\
\hline SS1 & 36.8 & 28.0 & 21.1 & 44.4 & 26.3 & 29.4 & 42.1 & 10.1 & 5.3 & 20.0 & 26.3 & 29.4 \\
\hline SS2 & 58.3 & 28.6 & 8.3 & 28.6 & 41.7 & 47.6 & 45.8 & 18.6 & 4.2 & 20.0 & 16.7 & 14.8 \\
\hline SS3 & - & - & 28.6 & 16.7 & 19.1 & 22.2 & - & - & 23.8 & 16.7 & 9.5 & 9.1 \\
\hline AGP & 88.5 & 54.8 & 92.3 & 57.1 & 92.3 & 66.7 & 3.9 & 50.0 & 80.8 & 51.2 & 73.1 & 59.4 \\
\hline WAT & 95.8 & 100.0 & 87.5 & 91.3 & 91.7 & 95.7 & 100.0 & 100.0 & 91.7 & 100.0 & 91.7 & 100.0 \\
\hline WET & - & - & 26.7 & 20.0 & 20.0 & 37.5 & - & - & 13.3 & 7.7 & 6.7 & 14.3 \\
\hline URB & - & - & 60.9 & 35.9 & 17.4 & 33.3 & 43.5 & 32.3 & 60.9 & 34.2 & 56.5 & 50.0 \\
\hline OCA & & & & & & & & & & & & \\
\hline OKC & & & & & & & & & & & & \\
\hline
\end{tabular}

Notes: (1) Abbreviations used in the land cover classification system: UPF, FLF, and LIF represent upland, flooding and liana forest classes; SS1, SS2 and SS3 represent initial, intermediate, and advanced succession stages; AGP represents agropasture; WAT, WET and URB represent non-vegetation land covers, i.e., water, wetland, and urban.

(2) Abbreviations used in accuracy assessment: PA and UA represent producer's accuracy and user's accuracy; OCA and OKC represent overall classification accuracy and overall kappa coefficient.

(3) Abbreviations for images: HH, HV, NL and text represent polarization options HH and HV, normalization image based on HH and HV, and the textural images developed from the $\mathrm{HH}, \mathrm{HV}$ and $\mathrm{NL}$ images respectively.

(4) Data scenarios: HH- (or HV-, NL-)text represent the textural images developed from HH (or HV, or NL) image; HH\& (HV\&, NL\&)text represent the combination of HH (or $\mathrm{HV}$, or $\mathrm{NL}$ ) image and corresponding textural images.

images from $\mathrm{HH}, \mathrm{HV}$, and NL. For the same scenario between L- and C-band data, L-band data provided much better classification than C-band data.

The above analyses are based on overall classification performance, and producer's accuracy and user's accuracy for each individual class, but do not show the misclassification among landcover types. As examples, Table 6 provides the error matrices from the combination of $\mathrm{HH}, \mathrm{HV}$, and their related textural images for both L-band and C-band data. L-band data can provide relatively good classification accuracy for flooding forest, SS2, agropasture, water, and urban, but perform poorly for liana forest, SS3, and wetland. C-band data perform relatively well for agropasture, water and urban, but very poorly for other land cover types, especially the vegetation classes. Therefore, this study indicates that neither L-band nor C-band data are suitable for the classification of detailed vegetation types such as different SS stages in the tropical moist region.

Since individual L-band or C-band data are difficult for landcover classification in this study, we evaluated whether the combination of L-band and C-band data would improve classification. Table 7 provides the classification results based on the combination of L-band and C-band data. As a comparison, overall accuracy and kappa coefficient for the same scenarios from individual L-band and C-band data were also included in this table. Table 7 showed that the combination of pure radiometric or textural images did not improve classification compared to only L-band data, but the combination of all radiometric and textural images from both L- and C-band data improved overall accuracy by $6.6 \%$ compared to only L-band data. The error matrix in Table 8 shows the same misclassification problem, as shown in Table 6, but 
Table 5

Comparison of land-cover classification results based on different combinations of HH and HV, or HH, HV, and NL and their combinations with related textural images from ALOS PALSAR L-band and RADARSAT-2 C-band data.

\begin{tabular}{|c|c|c|c|c|c|c|c|c|c|c|c|c|}
\hline \multirow[t]{3}{*}{ Land-cover type } & \multicolumn{6}{|c|}{ ALOS PALSAR L-band } & \multicolumn{6}{|c|}{ RADARSAT-2 C-band } \\
\hline & \multicolumn{2}{|c|}{$\mathrm{HH} \& \mathrm{HV}$} & \multicolumn{2}{|c|}{ HH-\&HV-text } & \multicolumn{2}{|c|}{ HH\&HV\&text } & \multicolumn{2}{|c|}{ HH\&HV } & \multicolumn{2}{|c|}{ HH-\&HV-text } & \multicolumn{2}{|c|}{ HH\&HV\&text } \\
\hline & $\mathrm{PA}$ & UA & PA & UA & PA & UA & PA & UA & PA & UA & PA & UA \\
\hline UPF & 27.3 & 30.0 & 12.1 & 80.0 & 51.5 & 39.5 & - & - & 9.1 & 42.9 & 21.2 & 30.4 \\
\hline FLF & 80.0 & 54.6 & 6.7 & 50.0 & 73.3 & 61.1 & 20.0 & 18.8 & 6.7 & 6.7 & 13.3 & 8.0 \\
\hline LIF & - & - & - & - & 25.0 & 15.8 & - & - & 25.0 & 23.1 & 25.0 & 13.6 \\
\hline SS1 & 31.6 & 46.2 & 10.5 & 100.0 & 42.1 & 50.0 & 21.1 & 7.4 & 5.3 & 33.3 & 31.6 & 21.4 \\
\hline SS2 & 54.2 & 33.3 & 33.3 & 61.5 & 66.7 & 64.0 & 33.3 & 21.6 & 8.3 & 40.0 & 20.8 & 45.5 \\
\hline SS3 & 23.8 & 27.8 & 4.8 & 100.0 & 23.8 & 38.5 & 4.8 & 100.0 & - & - & 14.3 & 13.0 \\
\hline AGP & 88.5 & 53.5 & 80.8 & 61.8 & 76.9 & 62.5 & 46.2 & 22.6 & 38.5 & 47.6 & 73.1 & 57.6 \\
\hline WAT & 95.8 & 100.0 & 87.5 & 91.3 & 83.3 & 95.2 & 95.8 & 100.0 & 91.7 & 100.0 & 91.7 & 100.0 \\
\hline WET & 26.7 & 50.0 & 40.0 & 50.0 & 33.3 & 55.6 & - & - & 6.7 & 5.6 & 13.3 & 22.2 \\
\hline URB & 30.4 & 77.8 & 95.7 & 18.3 & 60.9 & 87.5 & 17.4 & 19.1 & 87.0 & 19.4 & 56.5 & 81.3 \\
\hline OCA & \multicolumn{2}{|c|}{48.11} & \multicolumn{2}{|c|}{40.57} & \multirow{2}{*}{\multicolumn{2}{|c|}{$\begin{array}{l}56.13 \\
0.507\end{array}$}} & \multicolumn{2}{|c|}{25.94} & \multicolumn{2}{|c|}{29.72} & \multicolumn{2}{|c|}{38.68} \\
\hline \multirow[t]{2}{*}{ OKC } & \multicolumn{2}{|c|}{0.417} & \multicolumn{2}{|c|}{0.332} & & & \multicolumn{2}{|c|}{0.173} & \multicolumn{2}{|c|}{0.217} & \multicolumn{2}{|c|}{0.317} \\
\hline & \multicolumn{2}{|c|}{ HH\&HV\&NL } & \multicolumn{2}{|c|}{ HH-\&HV-\&NL-text } & \multicolumn{2}{|c|}{ HH\&HV\&NL\&text } & \multicolumn{2}{|c|}{ HH\&HV\&NL } & \multicolumn{2}{|c|}{ HH-\&HV-\&NL-text } & \multicolumn{2}{|c|}{ HH\&HV\&NL\&text } \\
\hline UPF & 27.3 & 37.5 & 18.2 & 85.7 & 69.7 & 59.0 & - & - & 15.2 & 26.3 & 24.2 & 27.6 \\
\hline FLF & 80.0 & 54.6 & 26.7 & 66.7 & 86.7 & 59.1 & 6.7 & 8.3 & 20.0 & 17.7 & 20.0 & 7.3 \\
\hline LIF & 16.7 & 10.0 & 8.3 & 50.0 & - & - & 8.3 & 50.0 & 8.3 & 11.1 & 16.7 & 15.4 \\
\hline SS1 & 26.3 & 33.3 & 10.5 & 66.7 & 26.3 & 62.5 & 26.3 & 7.4 & - & - & - & - \\
\hline SS2 & 45.8 & 29.7 & 20.8 & 71.4 & 70.8 & 58.6 & 37.5 & 24.3 & 20.8 & 33.3 & 16.7 & 40.0 \\
\hline SS3 & 9.5 & 14.3 & 14.3 & 30.0 & 28.6 & 30.0 & - & - & 9.5 & 18.2 & 14.3 & 16.7 \\
\hline AGP & 92.3 & 55.8 & 96.2 & 58.1 & 92.3 & 60.0 & 57.7 & 31.9 & 76.9 & 43.5 & 84.6 & 56.4 \\
\hline WAT & 95.8 & 100.0 & 87.5 & 87.5 & 87.5 & 87.5 & 95.8 & 100.0 & 91.7 & 100.0 & 91.7 & 100.0 \\
\hline WET & 26.7 & 44.4 & 20.0 & 75.0 & 20.0 & 75.0 & - & - & 26.7 & 26.7 & 26.7 & 25.0 \\
\hline URB & 21.7 & 100.0 & 91.3 & 19.8 & 69.6 & 76.2 & 13.0 & 18.8 & 91.3 & 36.2 & 65.2 & 62.5 \\
\hline OCA & \multicolumn{2}{|c|}{45.75} & \multicolumn{2}{|c|}{42.92} & & & & & & & & \\
\hline ОКС & & & & & & & & & & & & \\
\hline
\end{tabular}

Notes: Abbreviations (1) used in the land cover classification system, (2) used in accuracy assessment, and (3) for images are the same as Table 4.

(4) Data scenarios: the “-" and "\&"in this table indicate "derived" and "combination," for example, HH-text indicates textural images derived from HH image, HH\&HV represents the combination of $\mathrm{HH}$ and $\mathrm{HV}$ images.

the combination of L- and C-band data improved upland forest and non-vegetation classes such as agropasture, water, wetland, and urban.

4.3. Comparison of classification results among scenarios on a coarse classification system

The above section showed the difficulty of detailed vegetation classification and the misclassification among upland forest, flooding forest, liana forest, SS2, and SS3, among agropasture, wetland, and SS1, and between upland forest and urban. Therefore, three forest classes were merged as forest and three succession classes were merged as succession to examine the classifications of both L-band and C-band data. Table 9 provides the classification results based on the scenarios of a coarse classification system. For L-band data, the combination of $\mathrm{HH}, \mathrm{HV}$, and their textural images or the combination of $\mathrm{HH}, \mathrm{HV}, \mathrm{NL}$, and their textural images provided the best classification with overall accuracy values of $72 \%$ and $74 \%$, respectively. For C-band data, the combination of NL and relevant textural images has the best classification accuracy, followed by the same scenarios as L-band data. Also the overall accuracy and kappa coefficient from C-band data are much lower than they are from L-band data. As indicated in Table 10, wetland was confused with other land cover types, and neither L-band nor C-band can separate it from other land cover types. Urban is a complex landscape because its different shapes and sizes result in a wide data range in L-band or C-band; thus, urban is often difficult to be separated from other land-cover types based on radar data. Fig. 4 provides a comparison of color composites of $\mathrm{HH}, \mathrm{HV}$, and $\mathrm{NL}$ as red, green and blue, respectively, from L-band (a) and C-band (b) data, and the land-cover classification images from the combination of

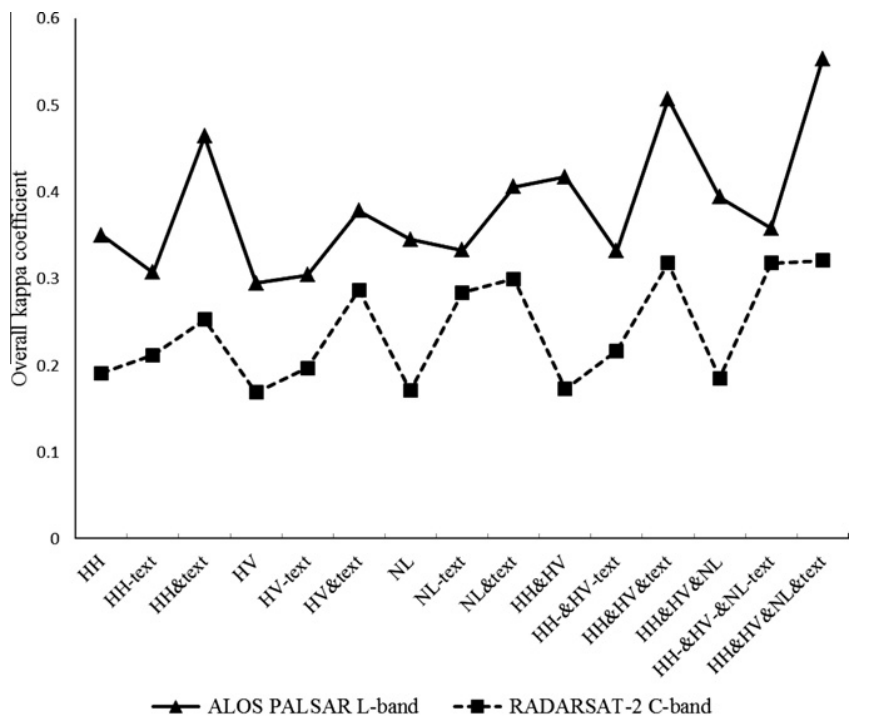

Fig. 3. Comparison of overall kappa coefficients among different datasets and between ALOS PALSAR L-band and RADARSAT-2 C-band.

$\mathrm{HH}, \mathrm{HV}$, and their textures based on L-band (c) and C-band (d). Comparing the color composites indicates that upland forest, flooding forest, and deforested areas (succession and agropasture) can be better visually interpreted in a L-band image than in a Cband image (Fig. $4 a$ and b). Comparing the classified images $c$ and $d$ in Fig. 4 indicates that urban and agropasture seem overestimated, especially in Fig. 4d. 
Table 6

A comparison of error matrices between L-band and C-band on the combination of $\mathrm{HH}, \mathrm{HV}$, and their textural images.

\begin{tabular}{|c|c|c|c|c|c|c|c|c|c|c|c|c|c|c|}
\hline & UPF & FLF & LIF & SS1 & SS2 & SS3 & AGP & WAT & WET & URB & RT & CT & PA & UA \\
\hline \multicolumn{15}{|c|}{ Combination of $H H, H V$, and their textural images from ALOS PALSAR L-band data } \\
\hline UPF & 17 & 2 & 6 & 1 & 2 & 8 & 0 & 0 & 0 & 7 & 43 & 33 & 51.5 & 39.5 \\
\hline FLF & 2 & 11 & 2 & 0 & 1 & 0 & 0 & 0 & 1 & 1 & 18 & 15 & 73.3 & 61.1 \\
\hline LIF & 10 & 1 & 3 & 0 & 2 & 3 & 0 & 0 & 0 & 0 & 19 & 12 & 25.0 & 15.8 \\
\hline SS1 & 1 & 0 & 0 & 8 & 1 & 1 & 2 & 0 & 3 & 0 & 16 & 19 & 42.1 & 50.0 \\
\hline SS2 & 0 & 0 & 0 & 2 & 16 & 4 & 0 & 1 & 2 & 0 & 25 & 24 & 66.7 & 64.0 \\
\hline SS3 & 3 & 1 & 1 & 1 & 2 & 5 & 0 & 0 & 0 & 0 & 13 & 21 & 23.8 & 38.5 \\
\hline AGP & 0 & 0 & 0 & 6 & 0 & 0 & 20 & 2 & 3 & 1 & 32 & 26 & 76.9 & 62.5 \\
\hline WAT & 0 & 0 & 0 & 0 & 0 & 0 & 1 & 20 & 0 & 0 & 21 & 24 & 83.3 & 95.2 \\
\hline WET & 0 & 0 & 0 & 0 & 0 & 0 & 3 & 1 & 5 & 0 & 9 & 15 & 33.3 & 55.6 \\
\hline URB & 0 & 0 & 0 & 1 & 0 & 0 & 0 & 0 & 1 & 14 & 16 & 23 & 60.9 & 87.5 \\
\hline
\end{tabular}

$\mathrm{OCA}=56.13 ; \mathrm{OKC}=0.507$

\begin{tabular}{llllllllllllll}
\multicolumn{2}{l}{ Combination } \\
UPF
\end{tabular}

$\mathrm{OCA}=38.68 ; \mathrm{OKC}=0.317$

Notes: Abbreviations (1) used in the land cover classification system, (2) used in accuracy assessment, and (3) for images are the same as Table 4.

(4) RT and CT represent row total and column total.

Table 7

Comparison of land-cover classification results from the combination of ALOS PALSAR L-band and RADARSAT-2 C-band data among different combination options.

\begin{tabular}{|c|c|c|c|c|c|c|}
\hline \multirow[t]{2}{*}{ Land-cover type } & \multicolumn{2}{|c|}{ L\&C HH\&HV } & \multicolumn{2}{|c|}{ L \& C HH-\&HV-text } & \multicolumn{2}{|c|}{ L \& C HH\&HV\&text } \\
\hline & PA & UA & PA & UA & PA & UA \\
\hline UPF & 33.3 & 39.3 & 3.0 & 33.3 & 66.7 & 51.2 \\
\hline FLF & 73.3 & 50.0 & 6.7 & 50.0 & 66.7 & 58.8 \\
\hline LIF & 25.0 & 16.7 & - & - & 25.0 & 20.0 \\
\hline SS1 & 31.6 & 40.0 & - & - & 36.8 & 70.0 \\
\hline SS2 & 41.7 & 34.5 & 16.7 & 80.0 & 54.2 & 72.2 \\
\hline SS3 & 19.1 & 23.5 & 4.8 & 100.0 & 38.1 & 40.0 \\
\hline AGP & 88.5 & 53.5 & 88.5 & 67.7 & 84.6 & 61.1 \\
\hline WAT & 91.7 & 100.0 & 91.7 & 100.0 & 91.7 & 100.0 \\
\hline WET & 26.7 & 57.1 & 33.3 & 55.6 & 46.7 & 77.8 \\
\hline URB & 43.5 & 90.9 & 95.7 & 16.4 & 82.6 & 86.4 \\
\hline OCA & 49.06 & & 37.26 & & 62.74 & \\
\hline ОКС & 0.429 & & 0.295 & & 0.581 & \\
\hline L-OCA & 48.11 & & 40.57 & & 56.13 & \\
\hline L-OKC & 0.417 & & 0.332 & & 0.507 & \\
\hline $\mathrm{C}-\mathrm{OCA}$ & 25.94 & & 29.72 & & 38.68 & \\
\hline $\mathrm{C}-\mathrm{OKC}$ & 0.173 & & 0.217 & & 0.317 & \\
\hline
\end{tabular}

Notes: Abbreviations (1) used in the land cover classification system, (2) used in accuracy assessment, and (3) for images are the same as in Table 4.

Table 8

Error matrix based on the combination of $\mathrm{HH}, \mathrm{HV}$, and their textural images from both L-band and C-band data.

\begin{tabular}{|c|c|c|c|c|c|c|c|c|c|c|c|c|c|c|}
\hline & UPF & FLF & LIF & SS1 & SS2 & SS3 & AGP & WAT & WET & URB & RT & CT & PA & UA \\
\hline UPF & 22 & 1 & 7 & 1 & 3 & 6 & 0 & 0 & 0 & 3 & 43 & 33 & 66.7 & 51.2 \\
\hline FLF & 4 & 10 & 1 & 0 & 0 & 2 & 0 & 0 & 0 & 0 & 17 & 15 & 66.7 & 58.8 \\
\hline LIF & 3 & 2 & 3 & 0 & 4 & 3 & 0 & 0 & 0 & 0 & 15 & 12 & 25.0 & 20.0 \\
\hline SS1 & 0 & 0 & 0 & 7 & 0 & 0 & 2 & 0 & 1 & 0 & 10 & 19 & 36.8 & 70.0 \\
\hline SS2 & 0 & 0 & 0 & 3 & 13 & 1 & 0 & 0 & 1 & 0 & 18 & 24 & 54.2 & 72.2 \\
\hline SS3 & 4 & 2 & 1 & 1 & 4 & 8 & 0 & 0 & 0 & 0 & 20 & 21 & 38.1 & 40.0 \\
\hline AGP & 0 & 0 & 0 & 6 & 0 & 1 & 22 & 0 & 6 & 1 & 36 & 26 & 84.6 & 61.1 \\
\hline WAT & 0 & 0 & 0 & 0 & 0 & 0 & 0 & 22 & 0 & 0 & 22 & 24 & 91.7 & 100.0 \\
\hline WET & 0 & 0 & 0 & 0 & 0 & 0 & 2 & 0 & 7 & 0 & 9 & 15 & 46.7 & 77.8 \\
\hline URB & 0 & 0 & 0 & 1 & 0 & 0 & 0 & 2 & 0 & 19 & 22 & 23 & 82.6 & 86.4 \\
\hline
\end{tabular}

Notes: Abbreviations (1) used in the land cover classification system, (2) used in accuracy assessment, and (3) for images are the same as in Table 4.

(4) RT and CT represent row total and column total. 
Table 9

Comparison of classification results based on a coarse classification system.

\begin{tabular}{|c|c|c|c|c|c|c|c|c|c|c|}
\hline \multirow[t]{2}{*}{ Land-cover type } & \multicolumn{2}{|c|}{ HH\&text } & \multicolumn{2}{|c|}{ HV\&text } & \multicolumn{2}{|c|}{ NL\&text } & \multicolumn{2}{|c|}{ HH\&HV\&text } & \multicolumn{2}{|c|}{ HH\&HV\&NL\&text } \\
\hline & PA & UA & PA & UA & PA & UA & PA & UA & PA & UA \\
\hline \multicolumn{11}{|c|}{ ALOS PALSAR L-band } \\
\hline Forest & 86.7 & 72.2 & 80.0 & 60.0 & 85.0 & 66.2 & 90.0 & 67.5 & 83.3 & 75.8 \\
\hline Succession & 67.2 & 64.2 & 67.2 & 65.2 & 50.0 & 57.1 & 62.5 & 74.1 & 67.2 & 75.4 \\
\hline Agropasture & 69.2 & 60.0 & 88.5 & 65.7 & 92.3 & 66.7 & 76.9 & 62.5 & 92.3 & 60.0 \\
\hline Water & 87.5 & 91.3 & 91.7 & 100.0 & 91.7 & 95.7 & 83.3 & 95.2 & 87.5 & 87.5 \\
\hline Wetland & 13.3 & 33.3 & 13.3 & 50.0 & 20.0 & 37.5 & 33.3 & 55.6 & 20.0 & 75.0 \\
\hline Urban & 52.2 & 85.7 & 4.4 & 20.0 & 17.4 & 33.3 & 60.9 & 87.5 & 69.6 & 76.2 \\
\hline OCA & \multicolumn{2}{|c|}{69.81} & \multicolumn{2}{|c|}{65.57} & \multicolumn{2}{|c|}{64.15} & \multicolumn{2}{|c|}{72.17} & \multicolumn{2}{|c|}{74.06} \\
\hline OKC & \multicolumn{2}{|c|}{0.608} & \multicolumn{2}{|c|}{0.549} & \multicolumn{2}{|c|}{0.538} & \multicolumn{2}{|c|}{0.641} & \multicolumn{2}{|c|}{0.668} \\
\hline \multicolumn{11}{|c|}{ RADARSAT-2 C-band } \\
\hline Forest & 46.7 & 41.8 & 48.3 & 48.3 & 51.7 & 51.7 & 55.0 & 47.8 & 66.7 & 48.8 \\
\hline Succession & 40.6 & 37.7 & 50.0 & 46.4 & 48.4 & 47.0 & 45.3 & 44.6 & 18.8 & 41.4 \\
\hline Agropasture & 73.1 & 57.6 & 65.4 & 41.5 & 73.1 & 61.3 & 65.4 & 54.8 & 84.6 & 56.4 \\
\hline Water & 91.7 & 100.0 & 91.7 & 100.0 & 91.7 & 100.0 & 91.7 & 100.0 & 91.7 & 100.0 \\
\hline Wetland & 13.3 & 40.0 & 13.3 & 28.6 & 6.7 & 14.3 & 13.3 & 22.2 & 26.7 & 25.0 \\
\hline Urban & 39.1 & 56.3 & 39.1 & 69.2 & 56.5 & 50.0 & 56.5 & 81.3 & 65.2 & 62.5 \\
\hline OCA & \multicolumn{2}{|c|}{50.00} & \multicolumn{2}{|c|}{52.36} & \multicolumn{2}{|c|}{55.19} & \multicolumn{2}{|c|}{54.72} & \multicolumn{2}{|c|}{54.25} \\
\hline OKC & \multicolumn{2}{|c|}{0.352} & \multicolumn{2}{|c|}{0.387} & \multicolumn{2}{|c|}{0.426} & \multicolumn{2}{|c|}{0.415} & \multicolumn{2}{|c|}{0.426} \\
\hline
\end{tabular}

Notes: OCA, overall classification accuracy; OKC, overall kappa coefficient; PA, producer's accuracy; UA, user's accuracy.

Table 10

A comparison of error matrices based on combinations of $\mathrm{HH}, \mathrm{HV}$, and their textural images between ALOS PALSAR L-band and RADARSAT-2 C-band data.

\begin{tabular}{|c|c|c|c|c|c|c|c|c|c|c|c|}
\hline Radar data & & Forest & SS & AGP & WAT & WET & URB & RT & CT & PA & UA \\
\hline \multirow[t]{7}{*}{ ALOS PALSAR L-band data } & Forest & 54 & 17 & 0 & 0 & 1 & 8 & 80 & 60 & 90.0 & 67.5 \\
\hline & Succession & 6 & 40 & 2 & 1 & 5 & 0 & 54 & 64 & 62.5 & 74.1 \\
\hline & Agropasture & 0 & 6 & 20 & 2 & 3 & 1 & 32 & 26 & 76.9 & 62.5 \\
\hline & Water & 0 & 0 & 1 & 20 & 0 & 0 & 21 & 24 & 83.3 & 95.2 \\
\hline & Wetland & 0 & 0 & 3 & 1 & 5 & 0 & 9 & 15 & 33.3 & 55.6 \\
\hline & Urban & 0 & 1 & 0 & 0 & 1 & 14 & 16 & 23 & 60.9 & 87.5 \\
\hline & OCA = 72.17; & $=0.641$ & & & & & & & & & \\
\hline \multirow[t]{7}{*}{ RADARSAT-2 C-band data } & Forest & 33 & 27 & 0 & 0 & 5 & 4 & 69 & 60 & 55.0 & 47.8 \\
\hline & Succession & 23 & 29 & 6 & 0 & 4 & 3 & 65 & 64 & 45.3 & 44.6 \\
\hline & Agropasture & 2 & 5 & 17 & 0 & 4 & 3 & 31 & 26 & 65.4 & 54.8 \\
\hline & Water & 0 & 0 & 0 & 22 & 0 & 0 & 22 & 24 & 91.7 & 100.0 \\
\hline & Wetland & 1 & 3 & 3 & 0 & 2 & 0 & 9 & 15 & 13.3 & 22.2 \\
\hline & Urban & 1 & 0 & 0 & 2 & 0 & 13 & 16 & 23 & 56.5 & 81.3 \\
\hline & OCA = 54.72; & $=0.415$ & & & & & & & & & \\
\hline
\end{tabular}

Notes: CT and RT represent column total and row total; OCA and OKC represent overall classification accuracy and overall kappa coefficient; PA and UA represent producer's accuracy; and user's accuracy.

\subsection{The role of textural images in land-cover classification}

The above analysis indicated that the incorporation of textural images from either L-band or C-band data into radiometric data is valuable for improving vegetation classification in the tropical moist region. One critical step in a study is to identify suitable textural images that can provide the best separability for the specified classes. This study designed a two-step method for identifying the best combination of textural images: (1) select the potential combination of textural images based on separability analysis of training sample plots, and (2) identify the best combination according to the standard deviation and correlation coefficients between the textural images. The results indicate that this method is effective in identifying suitable textural images for improving vegetation classification from a large number of textural images. However, use of textural images cannot assure improvements in all vegetation types, because textures vary with the characteristics of the landscape under investigation and the images used. In particular, the selection of a suitable size of moving window is important for a textural image, but no window size is perfect for all vegetation types because the patch sizes of the vegetation types vary greatly, from less than 1 ha for some successional vegetation to hundreds of hectares for primary forests. Therefore, there are tradeoffs among moving window size, spatial resolution of images, and the sizes of vegetation areas on the ground. For the selection of a single textural image, one can select the textural image with the highest separability, but for the selection of two or more textural images, the best combination approach provides an easy way to identify the combination of textural images suitable for improving land-cover classification. This study indicated that a single textural image has limited capability in land-cover classification, while more than two textures cannot significantly improve the classification performance. This conclusion based on radar data is similar to that based on optical sensor data (Lu et al., 2008; Li et al., 2011).

\subsection{Comparison of classification results from different algorithms}

A comparison of classification results from different algorithms indicated that compared to maximum likelihood classifier, both classification tree analysis and ARTMAP improved overall 

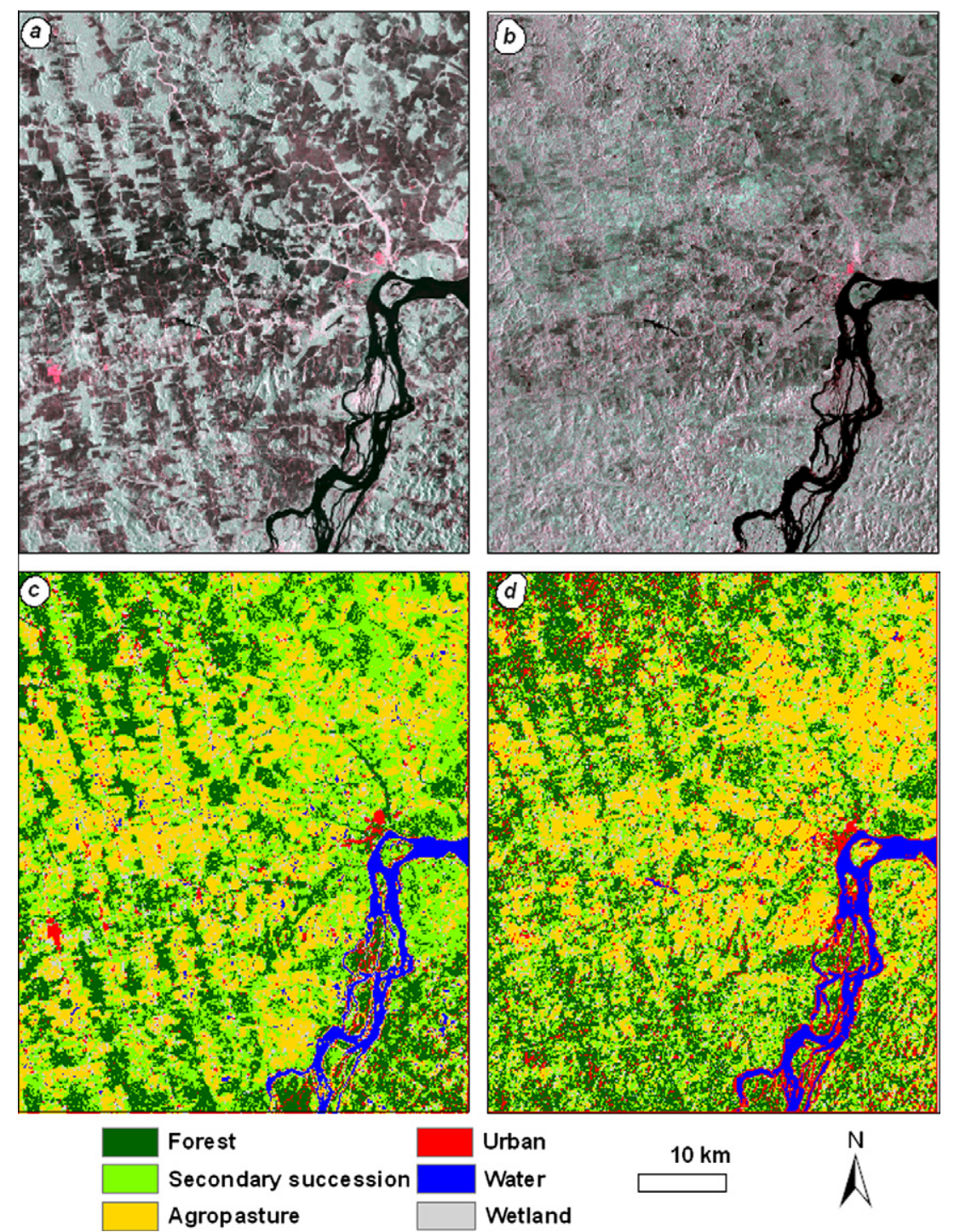

Fig. 4. A comparison of color composites and classification results (color composites based on ALOS PALSAR L-band (a) and RADARSAT C-band (b) HH, HV, and NL images assigned as red, green, and blue, respectively; land-cover classification images from ALOS PALSAR L-band (c) and RADARSAT C-band (d) HH, HV, and their corresponding textural images).

Table 11

Comparison of classification results from different classification algorithms based on the combination of ALOS PALSAR L-band HH, HV, and corresponding textural images.

\begin{tabular}{|c|c|c|c|c|c|c|c|c|c|c|c|c|}
\hline & \multicolumn{2}{|l|}{ MLC } & \multicolumn{2}{|l|}{ CTA } & \multicolumn{2}{|c|}{ ARTMAP } & \multicolumn{2}{|l|}{ K-NN } & \multicolumn{2}{|l|}{$\mathrm{OBC}$} & \multicolumn{2}{|l|}{ SVM } \\
\hline & PA & UA & PA & UA & PA & UA & PA & UA & PA & UA & PA & UA \\
\hline UPF & 51.5 & 39.5 & 81.8 & 50.0 & 75.8 & 39.7 & 21.2 & 33.3 & 33.3 & 44.0 & 84.9 & 40.0 \\
\hline FLF & 73.3 & 61.1 & 80.0 & 60.0 & 80.0 & 70.6 & 73.3 & 52.4 & 80.0 & 63.2 & 80.0 & 54.5 \\
\hline LIF & 25.0 & 15.8 & 16.7 & 25.0 & 16.7 & 100.0 & 25.0 & 14.3 & 58.3 & 21.2 & 0 & 0 \\
\hline SS1 & 42.1 & 50.0 & 31.6 & 66.7 & 26.3 & 55.6 & 36.8 & 46.7 & 42.1 & 53.3 & 31.6 & 85.7 \\
\hline SS2 & 66.7 & 64.0 & 58.3 & 77.8 & 45.8 & 64.7 & 54.2 & 32.5 & 62.5 & 68.2 & 37.5 & 60.0 \\
\hline SS3 & 23.8 & 38.5 & 14.3 & 25.0 & 23.8 & 38.5 & 19.1 & 26.7 & 28.6 & 35.3 & 14.3 & 33.3 \\
\hline AGP & 76.9 & 62.5 & 73.1 & 65.5 & 88.5 & 63.9 & 76.9 & 60.6 & 88.5 & 67.7 & 96.2 & 61.0 \\
\hline WAT & 83.3 & 95.2 & 95.8 & 92.0 & 100.0 & 92.3 & 95.8 & 100.0 & 91.7 & 88.0 & 95.8 & 88.5 \\
\hline WET & 33.3 & 55.6 & 20.0 & 33.3 & 33.3 & 62.5 & 33.3 & 41.7 & 20.0 & 75.0 & 13.3 & 50.0 \\
\hline URB & 60.9 & 87.5 & 73.9 & 60.7 & 60.9 & 66.7 & 34.8 & 72.7 & 60.9 & 77.8 & 52.2 & 66.7 \\
\hline OCA & \multicolumn{2}{|c|}{56.1} & \multicolumn{2}{|c|}{59.4} & \multicolumn{2}{|c|}{59.4} & \multicolumn{2}{|c|}{47.6} & \multicolumn{2}{|c|}{57.1} & \multicolumn{2}{|c|}{56.6} \\
\hline OKC & \multicolumn{2}{|c|}{0.5072} & \multicolumn{2}{|c|}{0.5417} & \multicolumn{2}{|c|}{0.5393} & \multicolumn{2}{|c|}{0.4158} & \multicolumn{2}{|c|}{0.5214} & \multicolumn{2}{|c|}{0.5057} \\
\hline
\end{tabular}

Notes: (1) MLC, maximum likelihood classifier; CTA, classification tree analysis; ARTMAP, a neural network classification method which synthesizes fuzzy logic and Adaptive Resonance Theory (ART) models; K-NN, K-nearest neighbor; OBC, object-based classification; and SVM, support vector machine.

(2) PA, UA, OCA and OKC represent producer's accuracy, user's accuracy, overall classification accuracy, and overall kappa coefficient.

(3) UPF, FLF and LIF represent upland, flooding and liana forests, SS1, SS2 and SS3 represent initial, intermediate, and advanced succession vegetation, AGP represent agropasture, WAT, WET and URB represent three non-vegetated classes, i.e., water, wetland and urban. 
accuracy by $3.3 \%$, mainly increasing upland forest and flooding forest classification accuracies (Table 11). Although object-based classification and support vector machine performances are similar to maximum likelihood classifier, object-based classification indeed improved flooding forest, liana forest, and agropasture, and support vector machine improved agropasture; however, knearest neighbor reduced overall accuracy by $8.5 \%$. Considering the time required for image classification, the order from shortest to longest times for the classification algorithms is maximum likelihood classifier, classification tree analysis, k-nearest neighbor, support vector machine, object-based classification, and ARTMAP. The order for highest to lowest overall accuracy is classification tree analysis, ARTMAP, object-based classification, support vector machine, maximum likelihood classifier, and k-nearest neighbor. After training samples were collected, maximum likelihood classifier rapidly finished the land-cover classification without further analyst involvement. Other nonparametric classifiers such as classification tree analysis, k-nearest neighbor, and ARTMAP require a lot of analyst's involvement in identifying suitable parameters for land-cover classification. Based on the classification accuracy, image processing time, and analyst's involvement in the classification procedure, maximum likelihood classifier and classification tree analysis were recommended methods for this type of study.

\section{Conclusions}

This study shows the difficulties presented by working with radar data and the importance of combining radiometric and textural images in land-cover classification in tropical moist regions. Overall, L-band data provided much better classification than C-band data. However, neither L-band nor C-band data can accurately separate detailed forest (e.g., upland forest, flooding forest, and liana forest) or succession (e.g., SS1, SS2, and SS3) classes. L-band data provided reasonably good classification accuracies for a coarse set of classes such as forest, secondary succession, agropasture, water, wetland, and urban with overall accuracy and kappa coefficient of $72.2 \%$ and 0.64 , respectively. However, C-band provided overall accuracy and kappa coefficient of only $54.7 \%$ and 0.42 for the same classification system. Compared to classification results from maximum likelihood classifier, both classification tree analysis and ARTMAP performed better by increasing overall accuracy of $3.3 \%$, object-based classifier and support vector machine performed similarly, and k-nearest neighbor performed poorly. Classification tree analysis and ARTMAP improved upland forest and flooding forest classification accuracies, but no algorithms can successfully separate different succession stages.

Based on this study, more specific conclusions are summarized as follows:

(1) The best texture measure varies, depending on different polarization options and wavelengths, but the best window sizes were $25 \times 25$ and $31 \times 31$. A combination of two textural images provided the best vegetation separability, and the combination of three or more textural images did not significantly improve vegetation separability.

(2) Considering single polarization images: The $\mathrm{HH}$ image from either L-band or C-band performs better than HV, and NL images did not improve performance compared to HH. Textural images from L-band $\mathrm{HH}, \mathrm{HV}$, or NL images provided similar or poor performances compared to corresponding radiometric images, but the textural images from C-band allow better performance than corresponding radiometric images. The combination of radiometric and textural images from either L-band or C-band polarizations improved classification compared to their individual datasets. For Lband data, textural images were less important than radiometric bands, however inversely for C-band data.

(3) Considering the combinations of different polarization images: For L-band data, the combination of $\mathrm{HH}$ and $\mathrm{HV}$ images improved classification, but adding the NL image did not; for C-band data, the combination of $\mathrm{HH}$ and $\mathrm{HV}$ or adding NL cannot improve classification compared to individual polarization images. Again, incorporation of textural images into radiometric data improved the classification compared to individual datasets.

(4) Considering combinations of different radar data: The combination of L-band and C-band $\mathrm{HH}$ and HV images yields very limited improvement, and combination of their textural images cannot improve the classification, but a combination of all radiometric and textural images indeed improved classification accuracy by $6.6 \%$.

(5) Comparison of classification results indicated that L-band data perform much better than C-band data, but both datasets cannot effectively separate fine vegetation classes. They are valuable for coarse land-cover classification.

(6) Compared to classification result from maximum likelihood classifier, the classification tree analysis and ARTMAP improved overall accuracy by 3.3\%. Considering image processing time and analyst's involvement in the classification procedure, maximum likelihood classifier and classification tree analysis are recommended for this type of study.

This study indicates that land-cover classification with radar data, either L-band or C-band, is a challenge, especially for fine land-cover classification system. However, radar data are valuable for coarse land-cover classification system, especially when optical sensor data are not available due to the cloud problem. More research should be on the exploration of using multitemporal radar data or the integration of radar and optical sensor data.

\section{Acknowledgments}

The authors thank National Science Foundation (Grant \#BCS 0850615) for funding this research. Luciano Dutra thanks JAXA (AO 108) Science Program for providing the ALOS PALSAR data and Mateus Batistella thanks the Canadian SOAR Program (\#SOAR Project 1957) for the RADARSAT-2 data used in this research. We also thank Anthony Cak for his assistance in the field work and Scott Hetrick for his assistance in organizing the field data.

\section{References}

Augusteijn, M.F., Clemens, L.E., Shaw, K.A., 1995. Performance evaluation of texture measures for ground cover identification in satellite images by means of a neural network classifier. IEEE Transactions on Geoscience and Remote Sensing 33 (3), 616-625.

Baghdadi, N., Boyer, N., El Todoroff, P., Hajj, M., Begue, A., 2009. Potential of SAR sensors TerraSAR-X, ASAR/ENVISAT and PALSAR/ALOS for monitoring sugarcane crops on Reunion Island. Remote Sensing of Environment 113 (8), 1724-1738.

Blaschke, T., 2010. Object based image analysis for remote sensing. ISPRS Journal of Photogrammetry and Remote Sensing 65 (1), 2-16.

Camps-Valls, G., Bruzzone, L., 2009. Kernel Methods in Remote Sensing Image Processing. John Wiley and Sons, Hoboken, NJ.

Carpenter, G.A., Crossberg, S., Reynolds, J.H., 1991. ARTMAP: supervised real time learning and classification of nonstationary data by a self-organizing neural network. Neural Networks 4, 565-588.

Chen, D., Stow, D.A., Gong, P., 2004. Examining the effect of spatial resolution and texture window size on classification accuracy: an urban environment case. International Journal of Remote Sensing 25 (11), 2177-2192.

Congalton, R.G., 1991. A review of assessing the accuracy of classification of remotely sensed data. Remote Sensing of Environment 37 (1), 35-46.

Congalton, R.G., Green, K., 2008. Assessing the Accuracy of Remotely Sensed Data: Principles and Practices, second ed. CRC Press, Boca Raton, FL.

Dutra, L.V., Huber, R., 1999. Feature extraction and selection for ERS-1/2 InSAR classification. International Journal of Remote Sensing 20 (5), 993-1016. 
Elnaggar, A.A., Noller, J.S., 2010. Application of remote-sensing data and decisiontree analysis to mapping salt-affected soils over large areas. Remote Sensing 2 (1), 151-165.

Evans, T.L., Costa, M., Telmer, K., Silva, T.S.F., 2010. Using ALOS/PALSAR and RADARSAT-2 to map land cover and seasonal inundation in the Brazilian Pantanal. IEEE Journal of Selected Topics in Applied Earth Observations and Remote Sensing 3 (4), 560-575.

Foody, G.M., 2002. Status of land cover classification accuracy assessment. Remote Sensing of Environment 80 (1), 185-201.

Foody, G.M., 2009. Classification accuracy comparison: hypothesis tests and the use of confidence intervals in evaluations of difference, equivalence and noninferiority. Remote Sensing of Environment 113 (8), 1658-1663.

Franklin, S.E., Hall, R.J., Moskal, L.M., Maudie, A.J., Lavigne, M.B., 2000. Incorporating texture into classification of forest species composition from airborne multispectral images. International Journal of Remote Sensing 21 (1), 61-79.

Franklin, S.E., Wulder, M.A., 2002. Remote sensing methods in medium spatia resolution satellite data land cover classification of large areas. Progress in Physical Geography 26 (2), 173-205.

Franklin, S.E., Wulder, M.A., Lavigne, M.B., 1996. Automated derivation of geographic window sizes for remote sensing digital image texture analysis Computers and Geosciences 22 (6), 665-673.

Frery, A.C., Correia, A.H., Freitas, C.C., 2007. Classifying multifrequency fully polarimetric imagery with multiple sources of statistical evidence and contextual information. IEEE Transactions on Geoscience and Remote Sensing 45 (10), 3098-3109.

Friedl, M.A., Brodley, C.E., 1997. Decision tree classification of land cover from remotely sensed data. Remote Sensing of Environment 61 (3), 399-409.

Gamba, P., Dell'Aqua, D., 2003. Increased accuracy multiband urban classification using a neuron-fuzzy classifier. International Journal of Remote Sensing 24 (4), 827-834.

Haralick, R.M., Shanmugam, K., Dinstein, I., 1973. Textural features for image classification. IEEE Transactions on Systems Man and Cybernetics SMC-3 (6), 610-620.

Jensen, J.R., 2005. Introductory Digital Image Processing: A Remote Sensing Perspective, third ed. Prentice Hall, Upper Saddle River, New Jersey.

Kasischke, E.S., Melack, J.M., Dobson, M.C., 1997. The use of imaging radars for ecological applications: a review. Remote Sensing of Environment 59 (2), 141156.

Kashyap, R.L., Chellappa, R., Khotanzad, A., 1982. Texture classification using features derived from random field models. Pattern Recognition Letters 1 (1), 43-50.

Landgrebe, D.A., 2003. Signal Theory Methods in Multispectral Remote Sensing. John Wiley and Sons, Hoboken, NJ.

Lee, J.S., Jurkevich, I., Dewaele, P., Wambacq, P., Oosterlinck, A., 1994. Speckle filtering of synthetic aperture radar images: a review. Remote Sensing Reviews $8(4), 313-340$

Li, G., Lu, D., Moran, E., Hetrick, S., 2011. Land-cover classification in a moist tropical region of Brazil with Landsat TM imagery. International Journal of Remote Sensing 32 (23), 8207-8230.

Li, Z., 2008. Fuzzy ARTMAP based neurocomputational spatial uncertainty measures. Photogrammetric Engineering \& Remote Sensing 74 (12), 15731584

Lu, D., Mausel, P., Batistella, M., Moran, E., 2004. Comparison of land-cover classification methods in the Brazilian Amazon basin. Photogrammetric Engineering \& Remote Sensing 70 (6), 723-731.

Lu, D., Weng, Q., 2007. A survey of image classification methods and techniques for improving classification performance. International Journal of Remote Sensing 28 (5), 823-870.

Lu, D., Batistella, M., Moran, E., 2007. Land cover classification in the Brazilian Amazon with the integration of Landsat ETM+ and RADARSAT data. International Journal of Remote Sensing 28 (24), 5447-5459.

Lu, D., Batistella, M., Moran, E., de Miranda, E.E., 2008. A comparative study of Landsat TM and SPOT HRG images for vegetation classification in the Brazilian Amazon. Photogrammetric Engineering \& Remote Sensing 74 (3), 311-321.

Marceau, D.J., Howarth, P.J., Dubois, J.M., Gratton, D.J., 1990. Evaluation of the greylevel co-occurrence matrix method for land-cover classification using SPOT imagery. IEEE Transactions on Geoscience and Remote Sensing 28 (4), 513-519.

Martinez, J., Le Toan, T., 2007. Mapping of flood dynamics and spatial distribution of vegetation in the Amazon floodplain using multitemporal SAR data. Remote Sensing of Environment 108 (3), 209-223.

Maselli, F., Chirici, G., Bottai, L., Corona, P., Marchetti, M., 2005. Estimation of Mediterranean forest attributes by the application of K-NN procedures to multitemporal Landsat ETM+ images. International Journal of Remote Sensing 26 (17), 3781-3796
Mausel, P., Wu, Y., Li, Y., Moran, E., Brondízio, E., 1993. Spectral identification of succession stages following deforestation in Amazonia. Geocarto International 8 (4), 11-20.

McRoberts, R.R., Tomppo, E.O., 2007. Remote sensing support for national forest inventories. Remote Sensing of Environment 110 (4), 412-419.

Milne, A.K., Dong, Y., 2002. Vegetation mapping using JERS-1 SAR mosaic for northern Australia. International Journal of Remote Sensing 23 (7), 1475-1486.

Moran, E.F., 1981. Developing the Amazon. Indiana University Press, Bloomington, IN

Moran, E.F., Brondízio, E.S., 1998. Land-use change after deforestation in Amazônia In: Liverman, D., Moran, E.F., Rindfuss, R.R., Stern, P.C. (Eds.), People and Pixels: Linking Remote Sensing and Social Science. National Academies Press, Washington, DC, pp. 94-120.

Moran, E.F., Brondízio, E.S., Mausel, P., 1994a. Secondary succession. Research and Exploration $10(4), 458-476$.

Moran, E.F., Brondízio, E.S., Mausel, P., Wu, Y., 1994b. Integrating Amazonian vegetation, land use, and Satellite data. Bioscience 44 (5), 329-338.

Mountrakis, G., Im, J., Ogole, C., 2011. Support vector machines in remote sensing: a review. ISPRS Journal of Photogrammetry and Remote Sensing 66 (3) 247-259.

ndi Nyoungui, A., Tonye, E., Akono, A., 2002. Evaluation of speckle filtering and texture analysis methods for land cover classification from SAR images. International Journal of Remote Sensing 23 (9), 1895-1925.

Pal, M., Mather, P.M., 2003. An assessment of the effectiveness of decision tree methods for land cover classification. Remote Sensing of Environment 86 (4), 554-565.

Park, N.W., 2010. Accounting for temporal contextual information in land-cover classification with multi-sensor SAR data. International Journal of Remote Sensing 31 (2), 281-298.

Park, N.W., Chi, K.H., 2008. Integration of multitemporal/polarization C-band SAR data sets for land-cover classification. International Journal of Remote Sensing 29 (16), 4667-4688.

Perumal, K., Bhaskaran, R., 2009. SVM-based effective land use classification system for multispectral remote sensing images. International Journal of Computer Science and Information Security 6 (2), 97-105.

Podest, E., Saatchi, S., 2002. Application of multiscale texture in classifying JERS-1 radar data over tropical vegetation. International Journal of Remote Sensing 23 (7), 1487-1506.

Rajesh, K., Jawahar, C.V., Sengupta, S., Sinha, S., 2001. Performance analysis of textural features for characterization and classification of SAR images. International Journal of Remote Sensing 22 (8), 1555-1569.

Rakwatin, P., Longepe, N., Isoguchi, O., Shimada, M., Uryu, Y., 2010. Mapping tropical forest using ALOS PALSAR $50 \mathrm{~m}$ resolution data with multiscale GLCM analysis. In: IEEE International Geoscience and Remote Sensing Symposium (IGARSS), pp. 1234-1237.

Rogan, J., Franklin, J., Stow, D., Miller, J., Woodcock, C., Roberts, D., 2008. Mapping land-cover modifications over large areas: a comparison of machine learning algorithms. Remote Sensing of Environment 112 (5), 2272-2283.

Rosenqvist, A., Shimada, M., Ito, N., Watanabe, M., 2007. ALOS PALSAR: a pathfinder mission for global-scale monitoring of the environment. IEEE Transactions on Geoscience and Remote Sensing 45 (11), 3307-3316.

Saatchi, S.S., Nelson, B., Podest, E., Holt, J., 2000. Mapping land cover types in the Amazon Basin using $1 \mathrm{~km}$ JERS-1 mosaic. International Journal of Remote Sensing 21 (6-7), 1201-1234.

Sawaya, S., Haack, B., Idol, T., Sheoran, A., 2010. Land use/cover mapping with quadpolarization radar and derived texture measures near Wad Madani, Sudan. GIScience and Remote Sensing 47 (3), 1548-1603.

Sheoran, A., 2009. Land cover/use classification using optical and quad polarization radar imagery. Thesis, George Mason University, Fairfax, VA.

Smits, P.C., Dellepiane, S.G., Schowengerdt, R.A., 1999. Quality assessment of image classification algorithms for land-cover mapping: a review and a proposal for a cost-based approach. International Journal of Remote Sensing 20 (8), 14611486 .

Tso, B., Mather, P.M., 2001. Classification Methods for Remotely Sensed Data. Taylor \& Francis, London

Wulder, M.A., Franklin, S.E., White, J.C., Linke, J., Magnussen, S., 2006. An accuracy assessment framework for large-area land cover classification products derived from medium-resolution satellite data. International Journal of Remote Sensing 27 (4), 663-683.

Yu, Q., Gong, P., Clinton, N., Biging, G., Kelly, M., Schirokauer, D., 2006. Object-based detailed vegetation classification with airborne high spatial resolution remote sensing imagery. Photogrammetric Engineering \& Remote Sensing 72 (7), 799811. 